CZASOPISMO INŻYNIERII LA¿OWEJ, ŚRODOWISKA I ARCHITEKTURY JOURNAL OF CIVIL ENGINEERING, ENVIRONMENT AND ARCHITECTURE

JCEEA, t. XXXIV, z. 64 (4/I/17), październik-grudzień 2017, s. 169-176, DOI:10.7862/rb.2017.203

\author{
Krzysztof BARAN ${ }^{1}$ \\ Marcin LEŚKO ${ }^{2}$ \\ Henryk WACHTA ${ }^{3}$
}

\title{
WIZUALIZACJA PRZEDWOJENNEJ ZABUDOWY DZIELNICY ŻYDOWSKIEJ W PRZEMYŚLU
}

\begin{abstract}
Dostępne obecnie aplikacje graficzne i moc obliczeniowa komputerów pozwalają na tworzenie złożonych modeli oraz animacji komputerowych. Powyższe aplikacje znalazły szerokie zastosowanie m.in. w architekturze do wirtualnej rekonstrukcji obiektów historycznych. Na podstawie archiwalnych map i zdjęć, tworzone są komputerowe modele obiektów, które pozwalają na odtworzenie i zobrazowanie istniejącej kiedyś zabudowy. Modelowanie komputerowe umożliwia również w stosunkowo krótkim czasie na wielowariantową koncepcję rekonstrukcji obiektu, co jest nieodzownym elementem wyboru optymalnej wersji rzeczywistej rekonstrukcji. W artykule przedstawiono komputerowe wizualizacje zabudowy Dzielnicy Żydowskiej w Przemyślu. Na podstawie dostępnych archiwalnych map i zdjęć zlokalizowano oraz zwymiarowano przedwojenne obiekty wchodzące w skład zabudowy Dzielnicy Żydowskiej. Przy wykorzystaniu zaawansowanej aplikacji graficznej 3ds Max Studio zwizualizowana została zabudowa Dzielnicy Żydowskiej, w skład której wchodziły m.in. Synagoga Tempel, Stara Synagoga, Sąd Grodzki oraz liczne zespoły kamienic. W artykule przedstawiono utworzone modele wybranych obiektów, rekonstrukcję komputerową całej Dzielnicy Żydowskiej, jak również przykład współczesnej aranżacji przestrzennej rekonstruowanej dzielnicy.
\end{abstract}

Slowa kluczowe: obiekty historyczne, rekonstrukcja, komputerowa wizualizacja, model komputerowy $3 \mathrm{~d}$, rendering

\section{Wprowadzenie}

Rekonstrukcja architektoniczna ma na celu odtworzenie obiektu lub jego części w formach historycznych, $\mathrm{z}$ wykorzystaniem zachowanych, oryginalnych elementów i detali [1]. Obecnie, wraz z postępem i rozwojem grafiki komputerowej, szczególne znaczenie w architekturze ma rekonstrukcja komputerowa, gdzie przy

${ }^{1}$ Autor do korespondencji / corresponding author: Krzysztof Baran, Politechnika Rzeszowska, Katedra Energoelektroniki, Elektroenergetyki i Systemów Złożonych, ul. Wincentego Pola 2, 35-959 Rzeszów; tel. 177432434; kbaran@prz.edu.pl

${ }^{2}$ Marcin Leśko, Politechnika Rzeszowska, Katedra Energoelektroniki, Elektroenergetyki i Systemów Złożonych, ul. Wincentego Pola 2, 35-959 Rzeszów; tel. 177432434; mlesko@prz.edu.pl

${ }^{3}$ Henryk Wachta, Politechnika Rzeszowska, Katedra Energoelektroniki, Elektroenergetyki i Systemów Złożonych, ul. Wincentego Pola 2, 35-959 Rzeszów; tel. 178651977; hwachta@prz.edu.pl 
wykorzystaniu aplikacji graficznych możliwe jest dokładne odtworzenie istniejących kiedyś obiektów architektonicznych [2]. Na podstawie archiwalnych map i zdjęć tworzony jest trójwymiarowy model obiektu, który następnie prezentowany jest na tle istniejącego zabudowania. Wykonana w ten sposób wizualizacja, umożliwia zobrazowanie w sposób bardzo zbliżony do rzeczywistego, przyjętej koncepcji rekonstrukcji obiektu. Komputerowe modelowanie umożliwia w dość szybki sposób przeanalizowanie wielu wariantów koncepcyjnych odbudowy obiektu, dzięki czemu, projektant na etapie wizualizacji ma możliwość wyboru optymalnego rozwiązania wpisującego się w istniejący stan zabudowy.

W artykule przedstawiono przykład komputerowego odtworzenia Dzielnicy Żydowskiej w Przemyślu. Z wykorzystaniem oprogramowania 3ds Max Studio odbudowane zostały główne obiekty zabudowy zniszczonej podczas II Wojny Światowej oraz przedstawiono możliwość współczesnej aranżacji zrekonstruowanej dzielnicy.

\section{Historyczna zabudowa Dzielnicy Żydowskiej w Przemyślu}

Przemyśl od wieków był miastem, w którym ścierały się różne kultury oraz narodowości. Liczną grupę ludności, oprócz Polaków i Rusinów stanowiła tutaj ludność żydowska i na początku XX wieku, liczebność ta wynosiła ok. 30\% populacji całego miasta.

Pierwsze wzmianki o ludności pochodzenia żydowskiego w Przemyślu pochodzą już z XI wieku, jednak na okres przypadający na drugą połowę XVI wieku, datuje się gwałtowny wzrost liczebności ludności żydowskiej, co związane było z nadaniem znacznych przywilejów rodzinom żydowskim przez króla Zygmunta Augusta. Druga połowa XVI wieku uznawana jest również za początek powstania Dzielnicy Żydowskiej w Przemyślu [3].

Dzielnica Żydowska znajdowała się pomiędzy ul. Wodną, ul. Jagiellońską oraz obecną ul. Kazimierzowską. Do najważniejszych obiektów wchodzących w skład dzielnicy wchodziły m.in.: Sąd Grodzki, Synagoga Tempel, Stara Synagoga oraz zespół kamienic.

$\mathrm{Na}$ rys. 1 została przedstawiona jedna $\mathrm{z}$ zachowanych pocztówek przedstawiająca przedwojenną zabudowę Dzielnicy Żydowskiej.

Działania wojenne sprawiły, że większość obiektów związanych z kulturą żydowską zostało zniszczonych, zachowały się jedynie dwie synagogi oraz cmentarz żydowski. Obecnie w miejscu Dzielnicy Żydowskiej znajduje się pusty plac, częściowo pełniący funkcję parkingu.

\section{Komputerowa rekonstrukcja zabudowy Dzielnicy Żydowskiej}

Na podstawie archiwalnych map i zdjęć ustalono lokalizację oraz gabaryty przedwojennych obiektów znajdujących się w Dzielnicy Żydowskiej. Na rys. 2 przedstawiono granice obiektów rekonstruowanych oraz istniejąca obecnie zabudowa. 


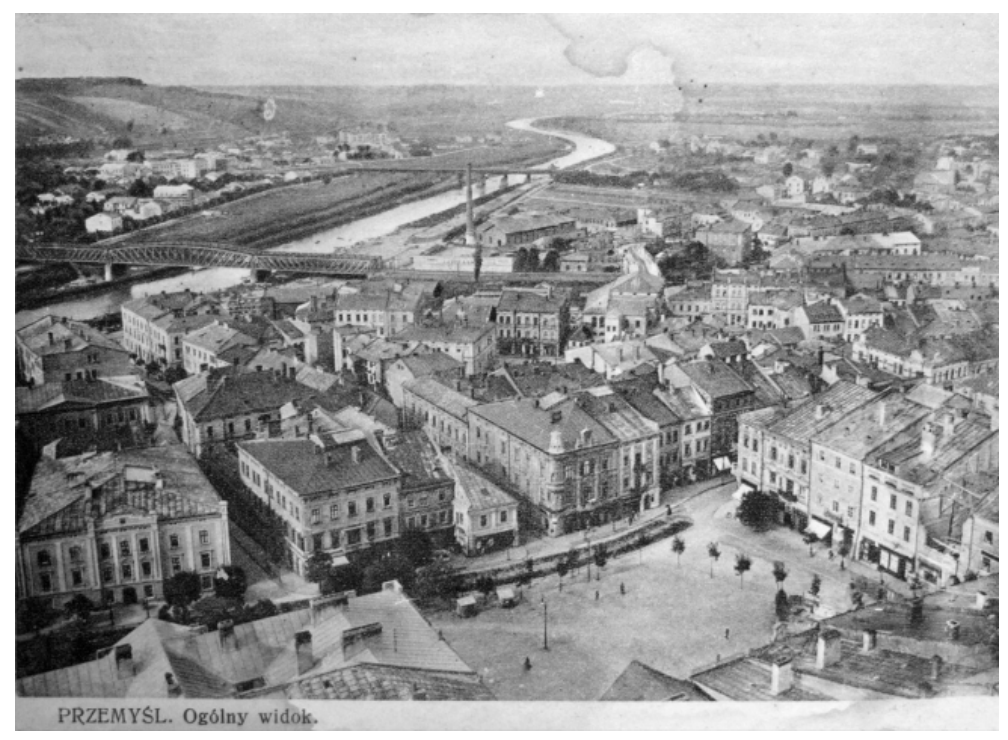

Rys. 1. Przedwojenna pocztówka przedstawiająca Dzielnicę Żydowską [4]

Fig. 1. Pre-war postcard showing Jewish District [4]

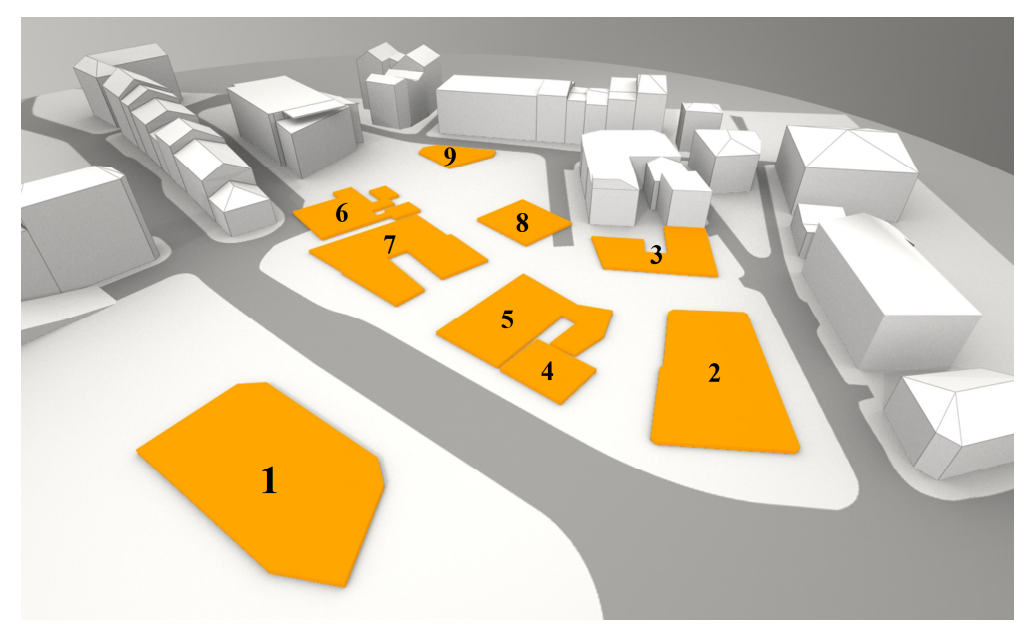

Rys. 2. Granice odtwarzanych obiektów oraz istniejąca zabudowa: 1 - Kamienica Nussbauma, 2 - Sąd Grodzki, 3 - Zespół kamienic przy ul. Wodnej, 4 - Synagoga Tempel, 5 - Zespół kamienic przy Synagodze Tempel, 6 - Stara Synagoga, 7 - Zespół kamienic przy Starej Synagodze, 8 - Kamienica w centrum Placu Berka Joselewicza, 9 - Kamienica przy ulicy Ratuszowej

Fig. 2. Boundaries of the reconstructed buildings and existing buildings : 1 - Nussbaum's house, 2 - Grodzki Court, 3 - Tenement houses on the Water Street, 4 - Tempel Synagogue, 5 - Tenement houses about Tempel Synagogue, 6 - Old Synagogue,

7 - Tenement houses about Old Synagogue, 8 - House in the center Berk Joselewicz square,

9 - House on the Town Hall Street 


\subsection{Sąd Grodzki}

Jednym z nielicznych obiektów Dzielnicy Żydowskiej, do którego zachowała się obszerna dokumentacja fotograficzna jest Sąd Grodzki. Był to budynek dwupiętrowy posiadający dużą ilość zdobień. Budynek ten zawierał charakterystyczne obramowania okienne, złożone gzymsy, ornamenty międzyokienne czy zdobnicze elementy dachu.

Na rys. 3 przedstawiono wykonany w oprogramowaniu 3ds Max Studio model Sądu Grodzkiego. Model ten jest bryłą o dużym stopniu złożoności co związane jest z dokładnym odwzorowaniem licznych detali.

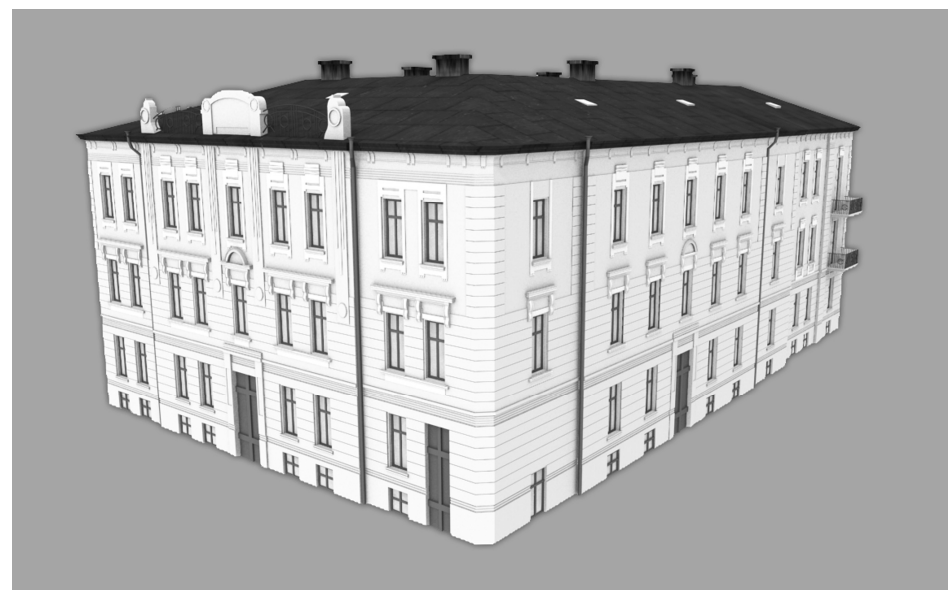

Rys. 3. Model komputerowy Sądu Grodzkiego [6]

Fig. 3. Computer model of the Grodzki Court [6]

\subsection{Synagoga Tempel}

Kolejnym charakterystycznym obiektem wchodzącym w skład zabudowy Dzielnicy Żydowskiej była synagoga Tempel. Obiekt ten wybudowany został końcem XIX w., murowany z czerwonej cegły na planie kwadratu. Do wejścia prowadziły szerokie schody, a charakterystycznym elementem synagogi były tablice Dekalogu wzniesione ku górze na frontowej ścianie [5].

\subsection{Stara Synagoga}

Synagoga zbudowana została końcem XVI w., odrestaurowana początkiem XIX w., niestety doszczętnie zniszczona działaniami wojennymi w 1941 r. Początkowo obiekt ten składał się z prostokątnej sali głównej, jednak w późniejszych latach dobudowane zostały liczne przybudówki, czego końcowym efektem była skomplikowana bryła obiektu [5]. 


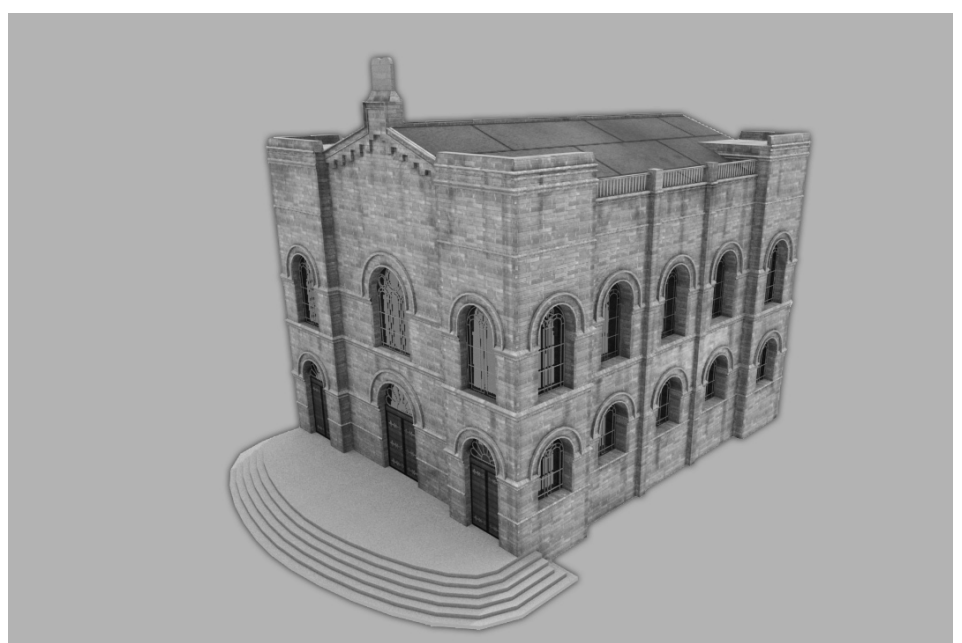

Rys. 4. Model komputerowy Synagogi Tempel [6]

Fig. 4. Computer model of the Tempel Synagogue [6]

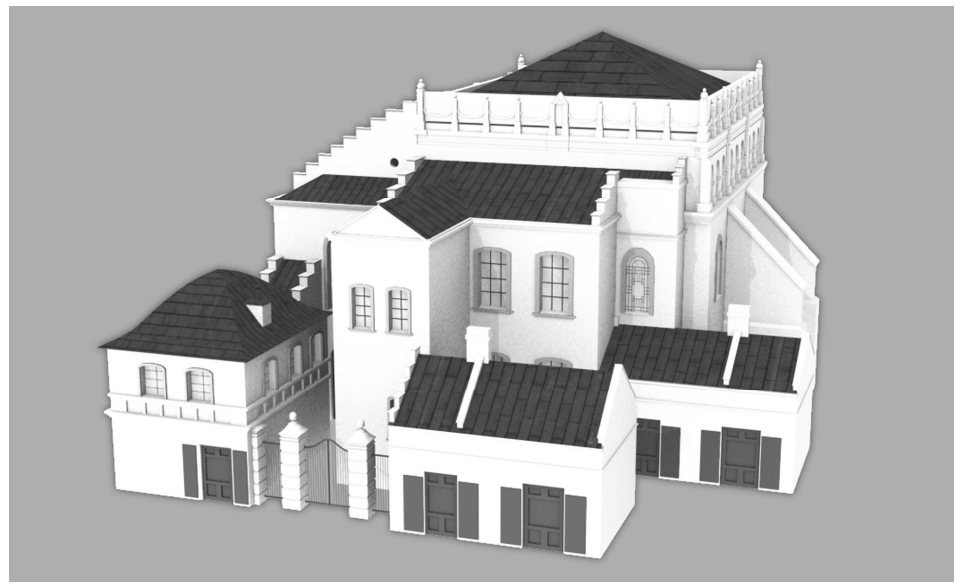

Rys. 5. Odtworzony komputerowo model Starej Synagogi [6]

Fig. 5. Computer model of the Old Synagogue [6]

\subsection{Dzielnica Żydowska}

Oprócz przedstawionych powyżej modeli, odtworzony został również zespół kamienic znajdujący się w sąsiedztwie wymienionych obiektów. Na rys. 6 i 7 przedstawiono całkowicie odtworzoną zabudowę przedwojennej Dzielnicy Żydowskiej. Białymi bloczkami zostały oznaczone istniejące obecnie zabudowania. 


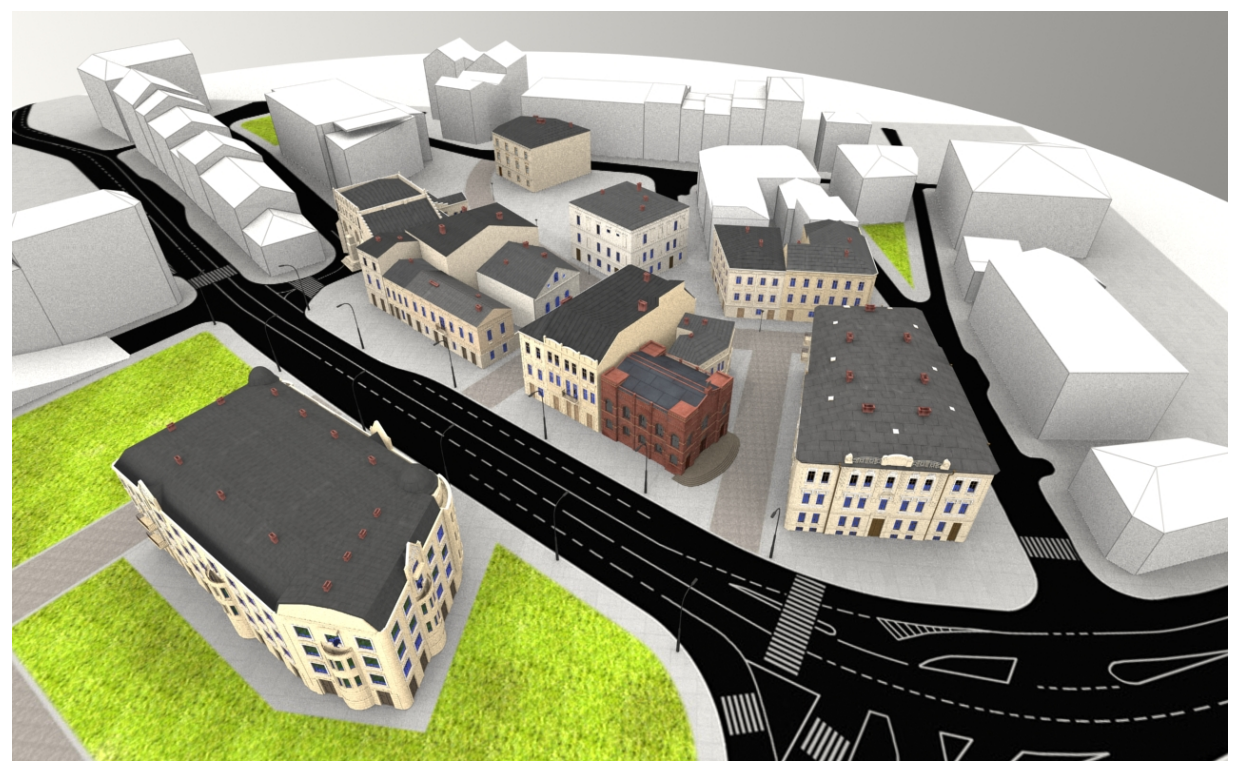

Rys. 6. Wirtualna rekonstrukcja zabudowy Dzielnicy Żydowskiej [6]

Fig. 6. Virtual reconstruction of buildings Jewish District [6]

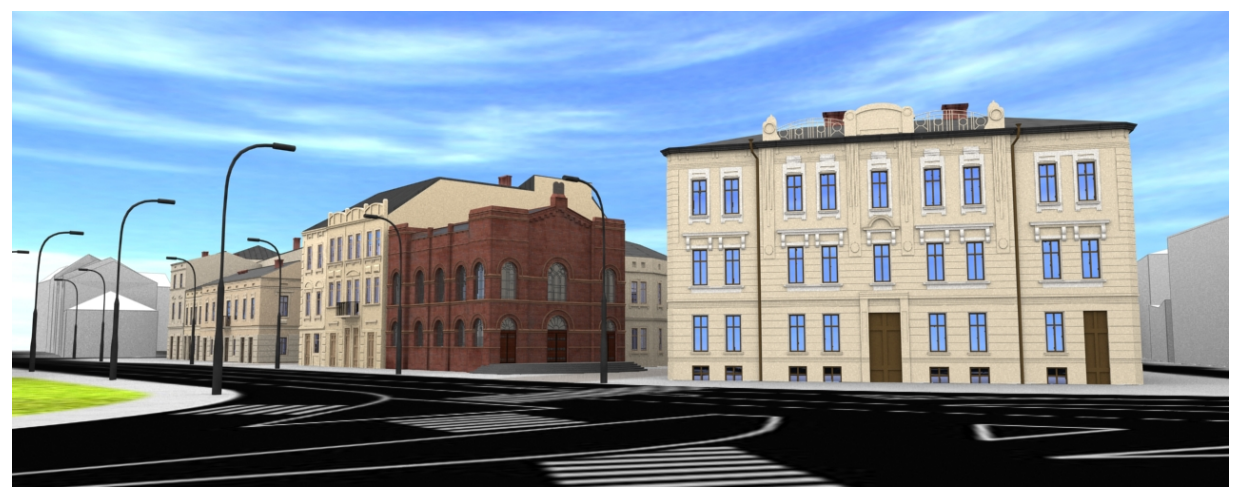

Rys. 7. Wizualizacja zabudowy Dzielnicy Żydowskiej [6]

Fig. 7. Visualisation of buildings Jewish District [6]

\section{Przykład współczesnej aranżacji przestrzennej dawnej Dzielnicy Żydowskiej}

W związku z obecnym planem miasta odnośnie zagospodarowania dawnej Dzielnicy Żydowskiej, który zakłada możliwość budowy obiektu wielkopowierzchniowego w tym miejscu, na rys 8 . został przedstawiony przykład 
współczesnej aranżacji wymienionego obszaru. Odtworzone obiekty historyczne połączone zostały szklanymi ścianami z metalowymi elementami konstrukcyjnymi. Przedstawiony wariant umożliwia umieszczenie pasaży handlowych i punktów usługowych wewnątrz obiektów, jednocześnie łącząc historyczne elewacje z nowoczesną formą i wyglądem.

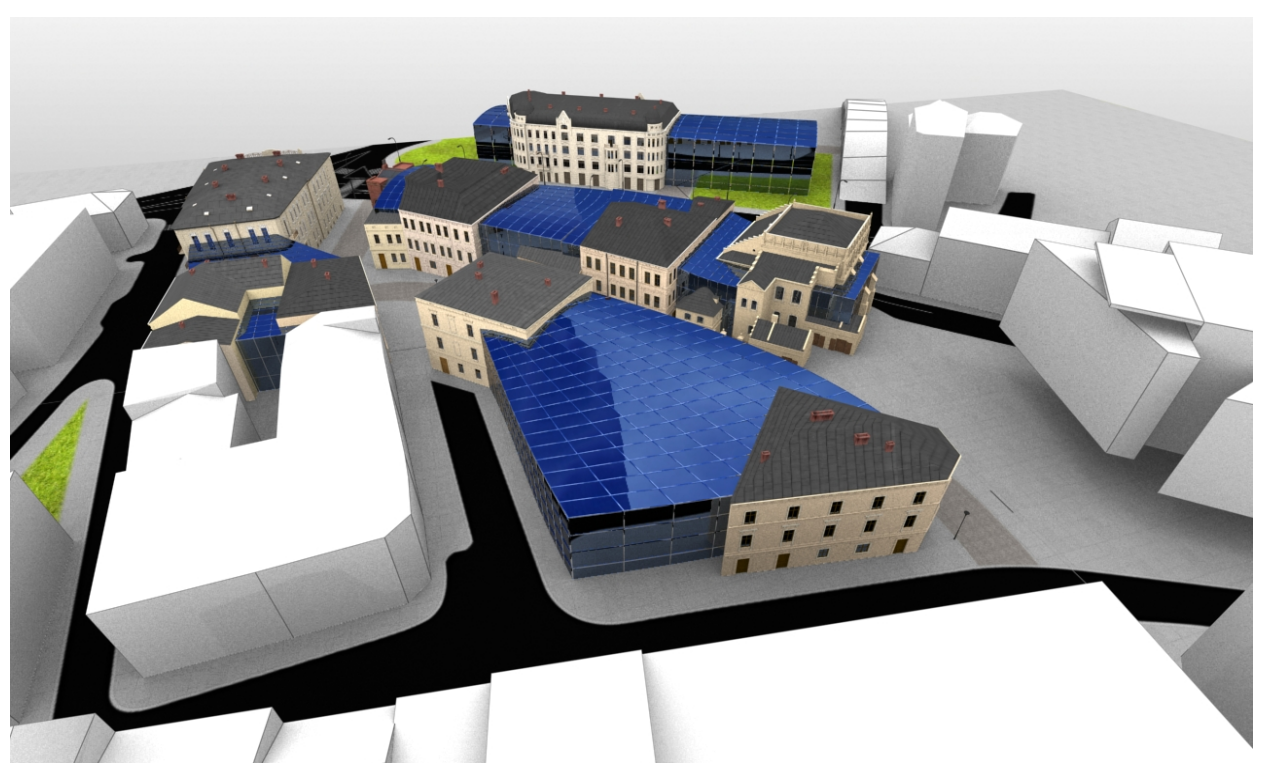

Rys. 8. Przykład współczesnej aranżacji Dzielnicy Żydowskiej [6]

Fig.8. Example of modern arrangement Jewish District [6]

\section{Wnioski}

Modelowanie komputerowe stanowi jedną z głównych metod wirtualnej rekonstrukcji obiektów zabytkowych. Zaawansowane aplikacje graficzne umożliwiają precyzyjne odtworzenie istniejącej w przeszłości zabudowy, często o znaczeniu historycznym. Utworzone w ten sposób wizualizacje umożliwiają zobrazowanie istniejącej kiedyś zabudowy. dzięki czemu wykorzystywane są szeroko m.in. w muzealnictwie, np. do wirtualnego spaceru 3D.

W artykule zaprezentowano wirtualną rekonstrukcję dawnej Dzielnicy Żydowskiej w Przemyślu. Stworzone wizualizacje komputerowe umożliwiły odtworzenie bogatej i różnorodnej zabudowy Przemyśla, brutalnie zniszczonej działaniem nazistowskich Niemiec w okresie II wojny światowej. 


\section{Literatura}

[1] Kowalski T.: Rekonstrukcja zabytków architektury, Teoria a praktyka, Wydawnictwo PKZ, Warszawa 1985.

[2] Kulig A,: Rekonstrukcje architektoniczne - źródła i metody odtworzeń zabytków, Czasopismo Techniczne, z.7-A/2008, str.75-85.

[3] Błoński J.: Zaginiony świat-historia Żydów przemyskich, Przemyśl 2008.

[4] www.wojnawp.republika.pl/zydzi/zla.html \{dostęp 13.06.2016 r.\}.

[5] Koperski A, Rejniewicz Ł.: Tajemnice placu Berka Joselewicza w Przemyślu. Rezultat badań w rejonie żydowskiego miasta. Muzeum Narodowe Ziemi Przemyskiej, Przemyśl 2006.

[6] Praca wykonana w ramach działalności Koła Naukowego Elektroenergetyk (opiekun koła: dr inż. Henryk Wachta).

Praca zostata zrealizowana $z$ wykorzystaniem aparatury zakupionej w wyniku realizacji Projektu: "Budowa, rozbudowa i modernizacja bazy naukowo-badawczej Politechniki Rzeszowskiej", wspólfinansowanego ze środków Unii Europejskiej w ramach Regionalnego Projektu Operacyjnego Województwa Podkarpackiego na lata 2007-2013, Oś priorytetowa 1 - Konkurencyjna i innowacyjna gospodarka.

\section{RECONSTRUCTION OF THE BUILDINGS OF THE JEWISH DISTRICT IN PRZEMYŚL}

\section{S u m m a r y}

The currently available graphic applications and the computing power of the computers allow you to create complex models and computer animations. These applications are widely used, among others, in architecture for the reconstruction of historical buildings. On the basis of archival maps and images, the computer models of the buildings are created, which allow you to reconstruct and illustrate the once existing buildings. Computer modelling also enables, in a relatively short time, the multi-variant concept of the building reconstruction, what is an indispensable element of choosing the optimal version of the real reconstruction.

The article presents the computer reconstruction of the buildings of the Jewish District in Przemyśl. On the basis of the available archival maps and photos it was possible to locate and dimension the pre-war buildings belonging to the buildings of the Jewish District. By using the advanced graphics application of 3ds Max Studio the buildings of the Jewish District were reconstructed, which included, among others, the Tempel Synagogue, the Old Synagogue, the Grodzki Court and numerous complexes of tenement houses. The article presents the created models of the selected objects, the computer reconstruction of the whole Jewish District, as well as the example of the modern spatial arrangement of the reconstructed district.

Keywords: historical objects, reconstruction, visualization, 3d computer model, rendering

Przestano do redakcji: 17.06.2016 $r$.

Przyjęto do druku: 30.06 .2017 r. 